\title{
Cerebral venous sinus thrombosis: review of the demographics, pathophysiology, current diagnosis, and treatment
}

\author{
Aristotelis Filippidis, M.D., ${ }^{1}$ Eftychia Kapsalaki, M.D., Ph.D., ${ }^{2}$ \\ Gianna Patramani, M.D., ${ }^{3}$ and Kostas N. Fountas, M.D., Ph.D. ${ }^{1}$ \\ Departments of ${ }^{1}$ Neurosurgery, ${ }^{2}$ Radiology, and ${ }^{3}$ Neurology, University Hospital of Larissa, \\ School of Medicine, University of Thessaly, Larissa, Greece
}

\begin{abstract}
Cerebral venous sinus thrombosis (CVST) is a rare clinicopathological entity. The incidence of CVST in children and neonates has been reported to be as high as 7 cases per million people, whereas in adults the incidence is 3-4 cases per million. The predisposing factors to this condition are mainly genetic and acquired prothrombotic states and infection. The clinical picture of CVST is nonspecific, highly variable, and can mimic several other clinical conditions. Diagnosis of CVST is established with the implementation of neuroimaging studies, especially MR imaging and venography. Identification and elimination of the underlying cause, anticoagulation, proper management of intracranial hypertension, and anticonvulsant prophylaxis constitute cornerstones of CVST treatment. Newer treatment strategies such as endovascular thrombolysis and decompressive craniectomy have been recently used in the treatment of patients with CVST with variable success rates. Further clinical research must be performed to delineate the exact role of these newer treatments in the management of severe cases of CVST. The recent advances in the diagnosis and treatment of patients with CVST have significantly lowered the associated mortality and morbidity and have improved the outcome of these patients. (DOI: 10.3171/2009.8.FOCUS09167)
\end{abstract}

\section{KeY Words - anticoagulation - cerebral venous sinus thrombosis • magnetic resonance venography - outcome • prognosis}

$\mathrm{C}$ EREBRAL venous sinus thrombosis constitutes a rare but serious cerebrovascular disorder, which years ago..$^{39,42}$ The clinical evolution of this entity and its natural history differ significantly from the various subtypes of arterial stroke, while its clinical presentation is characterized by a wide spectrum of symptoms and signs, depicted in an increasing body of previously published studies. ${ }^{17,21,29,62,68}$ The initial reports concerning CVST, which were based on autopsy series, led to the underestimation of the actual incidence of CVST. ${ }^{2}$ More recently, the evolution of noninvasive diagnostic imaging methodologies such as CT angiography and venography, as well as MR imaging, angiography, and venography, ${ }^{47,56,57}$

\footnotetext{
Abbreviations used in this paper: $\mathrm{aPPT}=$ activated partial thromboplastin time; CVST = cerebral venous sinus thrombosis; DS = digital subtraction; EFNS = European Federation of Neurological Societies; ICP = intracranial pressure; ISCVT = International Study on Cerebral Vein and Dural Sinus Thrombosis; LMWH = lowmolecular-weight heparin; SAH = subarachnoid hemorrhage; SSS $=$ superior sagittal sinus.
}

enriched our knowledge regarding the full clinical spectrum of CVST and provided us with a more accurate estimation of its true incidence. , $^{2,8,11,62}$

The purpose of the current study is to review the pertinent literature concerning the most recent demographic data, current pathophysiological mechanisms, predisposing conditions, and the etiological factors to outline the recent advances in the early diagnosis and the prompt management of CVST.

\section{Incidence and Demographics}

Cerebral venous sinus thrombosis accounts for $0.5 \%$ of all stroke cases. ${ }^{8}$ The estimated incidence of CVST differs significantly between adult and pediatric populations. In adults, the incidence of CVST has been estimated to be as high as 3-4 cases per million people, while the respective incidence in children and neonates is higher and has been estimated to be as many as 7 cases per million. ${ }^{2,23,62}$ A pediatric multicenter study in the US showed that CVST affects predominantly children $<6$ months old. ${ }^{69}$ It has been reported that female sex rep- 


\section{A. Filippidis et al.}

resents a predisposing factor for developing CVST. ${ }^{32,62}$ This predisposing factor is well reflected by the fact that $75 \%$ of the reported adult CVST cases are women. ${ }^{32,62}$ This observation is probably related to conditions such as pregnancy, puerperium, and usage of oral contraceptives in the female population., ${ }^{2,22}$ Twelve cases per $100,000 \mathrm{de}-$ liveries are complicated by peripartum and postpartum sinus thrombosis. The observed frequency of CVST is slightly lower than that of peripartum and postpartum arterial stroke. ${ }^{2,45,46}$ Recent clinical series and review studies ${ }^{2,17,27,29,32,52,62}$ have confirmed the female predominance among patients suffering CVST, contrary to older reports postulating that males and females were equally affected. ${ }^{44}$ The age group of patients demonstrating the highest frequency of CVST is those between 20 and 40 years of age. 2,32

The largest CVST multicenter clinical study (the ISCVT, including 624 patients ${ }^{32}$ ) revealed valuable information regarding the anatomical location of the most commonly involved cerebral sinuses. The SSS was identified as the most commonly affected sinus (62\%), followed by the transverse sinuses (41.2-44.7\% for 1 sinus), the straight sinus (18\%), and the cavernous sinus (1.3\%). ${ }^{32}$ Both superior sagittal and transverse sinuses are affected in $30 \% .^{4}$

\section{Pathophysiology}

Two distinct pathophysiological theories have been developed for explaining the development of CVST. . $^{10,52,60,62,67}$ Each of these theories separately or in some cases simultaneously may be implicated in the development of CVST. 10,52,60,62,67 The entire underlying pathophysiological mechanism has not been experimentally proven due to insufficient experimental animal research data, but parts of the 2 proposed theories have been decoded and have been experimentally demonstrated.

The first theory postulates that the thrombosis of the cerebral veins along with the subsequent blood-brain barrier disruption and the thrombosis of the major venous sinuses result in intracranial hypertension. The thrombosis of cerebral veins increases the venous pressure, reduces the capillary perfusion pressure, and finally increases the blood volume. Collateral pathways of blood flow are recruited, while the function of the venous system in high pressures leads to the blood-brain barrier disruption and the development of vasogenic edema. Cerebral perfusion pressure and cerebral blood flow drops, lead to the failure of the most important indirect regulator of intracellular water content, the $\mathrm{Na}^{+} / \mathrm{K}^{+}$ATPase dependent pump. This cascade of events results in the development of cytotoxic edema. ${ }^{38}$ The described theoretical pathophysiological model implies the coexistence of vasogenic and cytotoxic edema in the development of CVST, a scenario that has been recently validated by the observations and the results of diffusion weighted and perfusion-weighted based MR imaging studies. ${ }^{15,72}$

The second pathophysiological mechanism theory relies on the direct thrombosis of major cerebral venous sinuses. The resulting higher pressure of the thrombosed sinuses (especially the SSS) impedes the absorption and the smooth circulation of the CSF from the subarachnoid space to the cerebral venous circulation via the arachnoid villi structures. The impairment of CSF absorption leads to the development of intracranial hypertension. ${ }^{10,11,62}$

\section{Causes and Risk Factors}

The catalog of factors that may predispose one to CVST is quite extensive and includes more than 100 different causes (Table 1). A systematic approach to identify potential risk factors should be guided by the principles of Virchow (blood stasis, modifications of the vascular wall, and blood rheology) to target all these conditions that may be involved in the development of CVST. Another approach should identify and outline those genetic and acquired systemic conditions that may predispose one to CVST. A lot of references to predisposing risk factors are presented in case reports or anecdotal observations in the literature, while a few categories of causative factors appear consistently in all the published large clinical series. ${ }^{6,17,27,32}$ Ferro et al..$^{32}$ provided us with the valuable observations and the significant results of the multicenter ISCVT and shed light on the causes and risk factors that predispose one to CVST development.

Interestingly, dual or even multifactorial causes have been identified in a large number of cases (44\%) as the ISCVT study demonstrated. ${ }^{32}$ In a significant number (approximating 15\%) of the reported cases no underlying cause can be identified, whereas the most frequently identified risk factors are genetic and acquired prothrombotic states, pregnancy and puerperium, and infections. ${ }^{11}$

The patient's age and sex play an important role in the stratification of the risk factors observed in different patient populations. In pediatric populations there are differences in causes of CVST between neonates and older children. Head and neck infections and chronic systemic illnesses usually affect older children, whereas perinatal complications and dehydration affect mostly neonates. ${ }^{23,59,71}$ Heller et al. ${ }^{40}$ emphasized the combination of a prothrombotic state and/or an underlying clinical condition as crucial factors for the development of CVST in children.

Similarly, young women taking oral contraceptives expose themselves to a well-identified risk factor for developing CVST. ${ }^{20,22,36,41,50,58}$ It is well known that thirdgeneration contraceptives substantially increase the risk of CVST. ${ }^{20}$ Likewise, the risk of CVST is increased during the last trimester of pregnancy and during the postdelivery period. ${ }^{12}$

Elderly patients with CVST are also a distinct group. The most common risk factors in this group are genetic and acquired prothrombotic states. However, in a significant percentage (37\%) of these patients, no specific risk factor could be identified. ${ }^{30}$

Prothrombotic states, either genetically imposed or acquired, represent a large component of the etiology and play an important role in the development of CVST. Antithrombin III, protein C, and protein S deficiencies among genetic thrombophilias are well known and relatively common predisposing conditions to the development of CVST. Less common thrombophilic conditions are muta- 


\section{Cerebral venous sinus thrombosis}

tions in Factor V Leiden, prothrombin (20210) and homocysteinemia induced by methylene tetrahydrofolate reductase gene mutations. Acquired prothrombotic states such as nephritic syndrome, hyperhomocysteinemia, and antiphospholipid antibodies have also been implicated in the development of CVST. Malignancy, hematological conditions, inflammatory systemic disorders, postoperative infections, and operative procedures also predispose one to CVST. Additionally, maneuvers that may directly or indirectly alter the cerebral venous circulation, such as lumbar punctures, cranial trauma, jugular catheter occlusion, and neurosurgical interventions, have been identified as common risk factors of CVST in primary or hospital care. . $^{10,29,32,62}$

Three large multicenter clinical studies representing different regions of the world revealed important differences among the CVST-associated risk factors and predisposing conditions, which require further consideration for developing more efficacious prophylaxis strategies. The ISCVT study by Ferro et al. ${ }^{32}$ mainly included patients from Europe and South America. The study conducted by Wasay et al. ${ }^{68}$ concerns the incidence of CVST in the US, while the study of Khealani et al. ${ }^{43}$ concerns CVST in Pakistan and the Middle East. The most common risk factor in the ISCVT study was thrombophilia, with a low frequency of observed hyperhomocysteinemia and infection. In contrast, the US study revealed a larger number of patients developing CVST due to homocysteinemia, while the study of Khealani et al. ${ }^{43}$ identified infection as the most common cause of CVST among their patients.

\section{Diagnosis}

\section{Clinical Presentation}

Cerebral venous sinus thrombosis demonstrates a highly variable clinical picture, such that the clinical presentation does not offer significant help in establishing the diagnosis. ${ }^{8,11,62}$ The nonspecific clinical presentation and its importance in making the diagnosis of CVST are reflected in the results of the ISCVT study, in which the median delay from the onset of symptoms to the diagnosis was 7 days. ${ }^{32}$ Similar delays can be oberved in the admission of patients with CVST in other studies. ${ }^{34}$ The clinical picture of CVST may be expressed as 4 distinct syndromes or combinations of them with significantly varied morbidity and mortality. ${ }^{29}$ The severity of CVST and the presenting clinical symptomatology as well as its overall outcome are affected by the patient's age and general medical condition, the anatomical location of the involved sinus and the associated cerebral veins, the extent and the degree of thrombosis, and the involvement of the cerebral parenchyma. ${ }^{32}$

Isolated intracranial hypertension can be the only pathophysiological abnormality of the first syndrome, in which the presentation of headache with or without vomiting, papilledema, visual disturbances, and possibly sixth cranial nerve palsy predominate in the clinical presentation. ${ }^{7}$ Headache is the most common presenting symptom among patients suffering CVST, occurring in as many as $89 \% .{ }^{32}$ However, headache is a nonspecific and generally common symptom, completely lacking any localizing significance and thus providing no clues for the involved sinus. ${ }^{3,11}$ The severity of the headache and its acute presentation mimic the characteristics of the headache usually noted in patients suffering SAH. In the majority of the cases, it consists of a dull, nonlocalized, acute pain, which can be reproduced or aggravated by maneuvers that raise the ICP (the Valsalva maneuver). Other types of headache such as thunderclap headache, or headache associated with aura, can be occasionally observed in patients with CVST. ${ }^{19}$ Headache may be the only neurological sign in patients with CVST. ${ }^{13,16}$ Papilledema can be observed in slowly developing CVST (in 28.3-47\%). ${ }^{32,52}$

The second clinical syndrome is often referred to in the pertinent literature as a focal syndrome, to emphasize the appearance of focal neurological deficits and/or epileptic episodes. About half of the patients with CVST develop cerebral parenchymal lesions and neurological signs. ${ }^{62}$ Hemiparesis or monoparesis are the most frequent focal neurological signs observed in patients with CVST, and the involvement of the SSS leads frequently to bilateral deficits. Thrombosis of the left transverse sinus can be the underlying cause of acute aphasia. Sensory neurological deficits are less frequently observed. Thrombosis of the straight sinus often leads to neuropsychological and cognitive deficits. Seizures can be observed in approximately $40 \%$ of patients with CVST. This percentage is much higher than the respective percentage of seizures in patients suffering arterial strokes. ${ }^{8,11,62}$ Focal seizures with limited extension account for about $50 \%$ of the seizures observed in CVST patients, but generalized seizures or status epilepticus can also be observed..$^{62}$ It has been demonstrated that parenchymal involvement and focal neurological deficits are associated with increased frequency of epileptic episodes. ${ }^{33}$

Encephalopathy is the third type of clinical syndrome that has been described in patients with CVST. Multifocal signs, changes in the level of consciousness leading eventually to coma, and a more diffuse pattern of neurological deficits are associated with the presence of parenchymal lesions, deep cerebral venous occlusion, and extensive sinus thrombosis. The clinical picture is quite dramatic in these cases. The majority of patients presenting with these symptoms are very old or very young, while 1 or more aggravating factors such as malignancy, cardiac disease, or pulmonary embolism are often present. ${ }^{52}$

The cavernous sinus syndrome is the fourth clinical syndrome of patients with CVST, ${ }^{29}$ which constitutes the least common clinical syndrome. Cavernous sinus syndrome is often accompanied by oculomotor nerve palsies, facial pain, or sensory loss in the distribution of the trigeminal nerve, proptosis, and chemosis. It is a very serious clinical condition, often caused by infections, and is associated with a poor prognosis. ${ }^{1,24,29}$

On rare occasions, patients with CVST may present with SAH, transient ischemic attacks, tinnitus, isolated psychiatric symptoms, and isolated or multiple cranial nerve palsies. ${ }^{8}$

\section{Differential Diagnosis}

Cerebral venous sinus thrombosis usually presents 

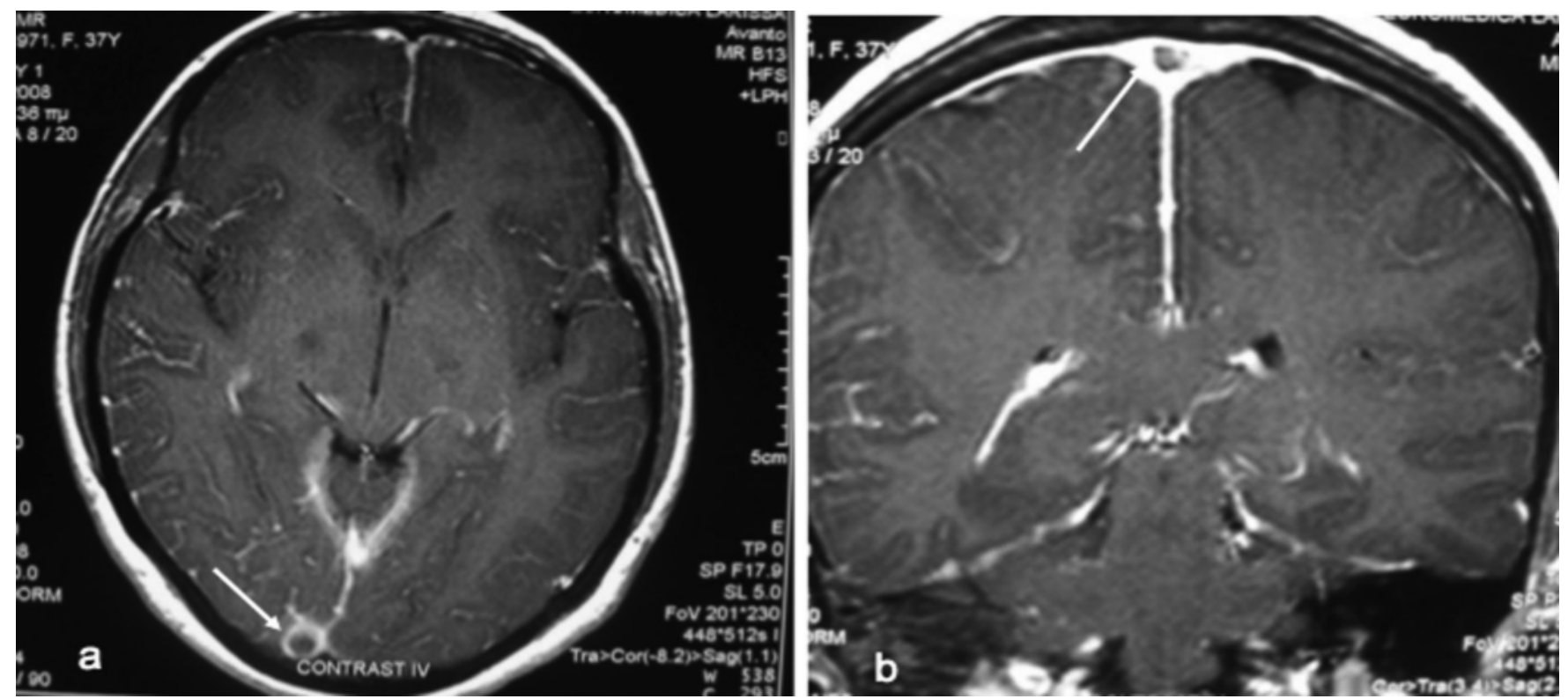

FIG. 1. Axial (a) and coronal (b) T1-weighted MR images after contrast administration showing a filling defect in the SSS (arrow) suggestive of sinus thrombosis (empty delta sign).

in a nonspecific and occasionally puzzling way, which does not aid in establishing a diagnosis. The differential diagnosis should include, but not be limited to, arterial stroke, ${ }^{55}$ meningeal or cerebral inflammatory disease, brain abscess, cerebral vasculitis, or endocarditis..$^{52}$

The differentiation between arterial stroke and CVST should rely on specific characteristics of these 2 distinct clinicopathological entities. The onset of CVST is subacute in the vast majority of cases, in contrast to the acute presentation of arterial stroke. There is also a more progressive evolution of the clinical presentation in patients with CVST. Increased ICP and seizures predominate in the clinical picture of CVST, whereas these are not common presenting symptoms in patients suffering arterial strokes. Furthermore, even in those cases in which a cerebral infarct has developed in a patient with CVST, the anatomical location of the infarct shows no characteristic arterial distribution as in the cases of arterial stroke. ${ }^{55}$ The association of neurological focal deficits with headache, seizures, or altered level of consciousness is highly suggestive of CVST. ${ }^{52}$

\section{Neuroimaging Studies}

The extensive and highly variable spectrum of clinical presentation in CVST cannot establish its diagnosis in the majority of the cases; therefore, neuroimaging studies are of paramount importance. Computed tomography, MR imaging, MR angiography and venography, multislice CT angiography and venography, and DS angiography constitute the current imaging armamentarium. 47,56,57,62

The initial imaging study in the evaluation of patients with possible CVST is usually a brain CT scan. The classical CT findings of CVST are the empty triangle or the empty delta sign, the cord sign, and the dense triangle sign. ${ }^{11,47,52}$ The empty delta sign is the absence of filling of the torcula on a CT scan after contrast injection (Fig. 1).
This sign is absent if the posterior part of the SSS is not involved or if the scan has been performed within 5 days of the onset of symptoms. ${ }^{52}$ The dense triangle sign or dense clot sign is the demonstration of fresh thrombus in the posterior part of the SSS in a CT scan without contrast administration, while the cord sign depicts hyperdense, thrombosed cortical cerebral veins ${ }^{56}$ (Fig. 2). However, these pathognomonic signs are only observed in approximately one-third of the cases. ${ }^{11,47,52}$ In addition to these pathognomonic CT characteristics there are also some imaging findings that may be indicative of CVST. These imaging findings are parenchymal abnormalities and contrast enhancement of the falx and the tentorium, as well as dilated cerebral veins, which have been developed for serving the newly formed collateral circulation. ${ }^{11}$

Magnetic resonance imaging, as well as MR angiography and venography, provide us with the most sensitive tools for detecting CVST. The combination of these imaging modalities constitutes the study of choice in the diagnosis of CVST. ${ }^{8,11,47}$ The MR imaging signal appearance of the sinus thrombus is variable during the time course

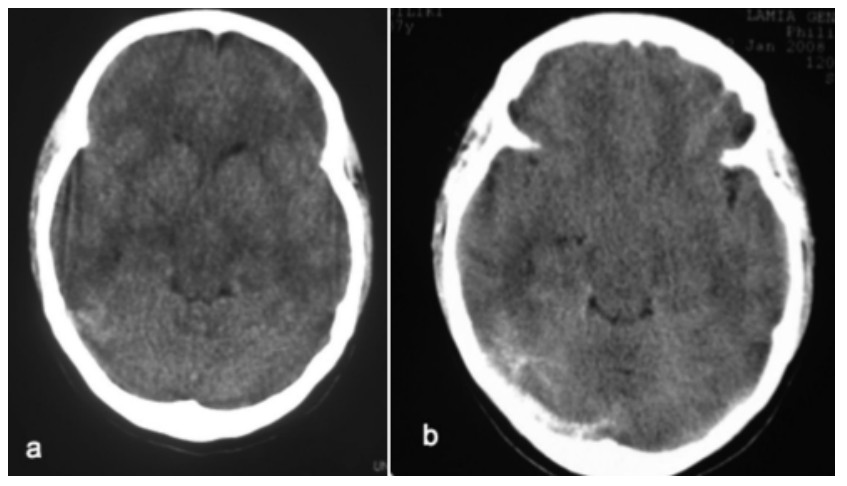

FIG. 2. Axial CT scans showing a hyperdense right transverse sinus and the presence of right temporal $\mathrm{SAH}$. 

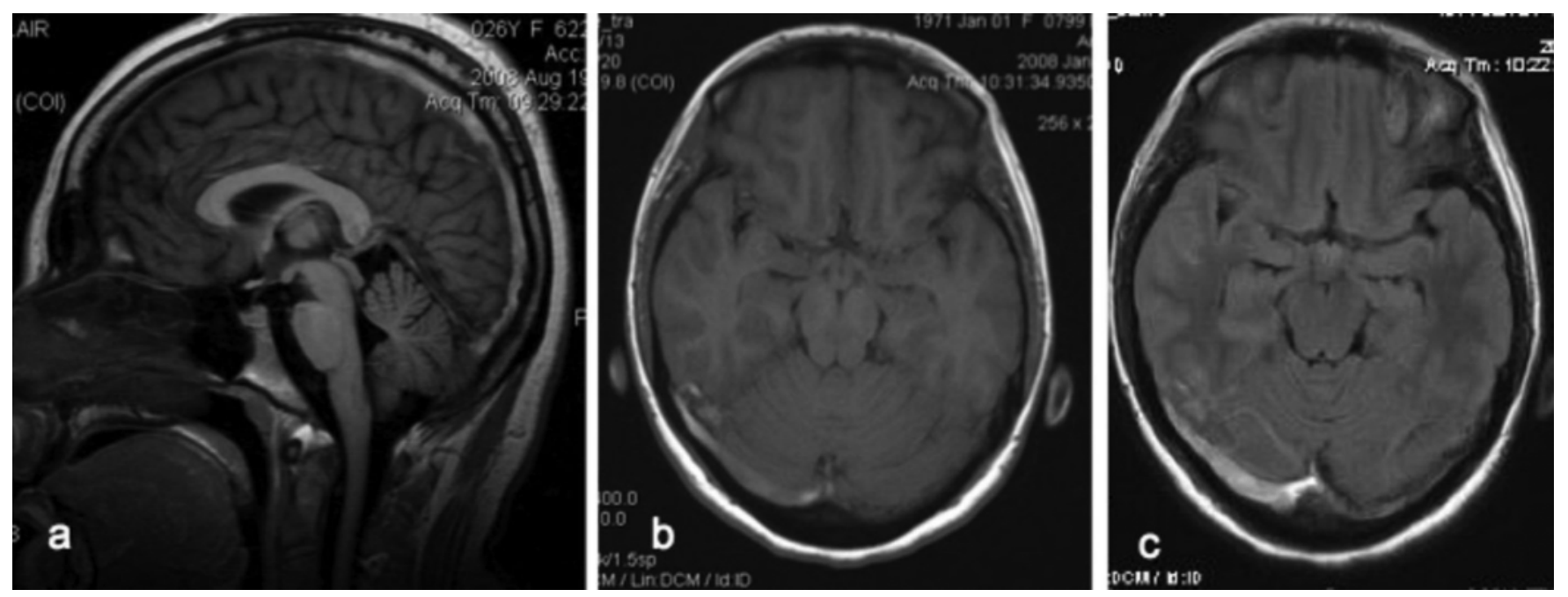

FIG. 3. Sagittal (a) and axial (b and c) T1-weighted MR images obtained in a 26-year-old pregnant female patient showing a hyperintense right transverse sinus and SSS, indicative of sinus thrombosis.

of CVST; therefore, the interpretation of the images needs to be performed with the knowledge of the signal behavior throughout the time of thrombus organization and its probable resolution. Thrombosed sinuses appear isointense on T1-weighted images and hypointense on T2weighted images during the first 3-5 days. ${ }^{8}$ After the first 5 days, the signal shows higher intensity on both T1- and T2-weighted MR imaging (Fig. 3), whereas 1 month after the CVST event, there is variability in the obtained signal from the thrombosed sinus, which may appear isointense. ${ }^{47,56,57,62}$ Despite the well-documented high sensitivity and specificity of MR imaging and MR venography in diagnosing CVST, there are a few reports in the literature of misdiagnosis due to MR imaging flow artifacts. ${ }^{8,70}$ Moreover, the accurate interpretation of the obtained MR imaging and MR venography studies require meticulous knowledge of the cerebral sinus anatomy and their com- mon variations such as left transverse sinus hypoplasia or atresia, which occurs in $49 \%$ of cases $^{74}$ and is often associated with hypoplasia of the ipsilateral jugular foramen. ${ }^{56}$ Additionally, the presence of prominent arachnoid granulations, ${ }^{47,56}$ SSS duplication, and other variations should not be confused with CVST. Use of DS angiography may clarify any anatomical variations. The interobserver agreement concerning CVST and DS angiography is low (62\%) compared with the higher MR imaging and MR venography interobserver agreement (94\%). ${ }^{11,35}$

Several studies report the usefulness of gradient echo T2*-weighted images in the diagnosis of CVST, especially in the isolated cortical venous type. According to these reports, in CVST sinuses appear hypointense on gradient echo T $2 *$-weighted images, and these sequences may be very helpful in the early stages of thrombosis (1-3 days), demonstrating quite high sensitivity. ${ }^{8}$ However, our expe-

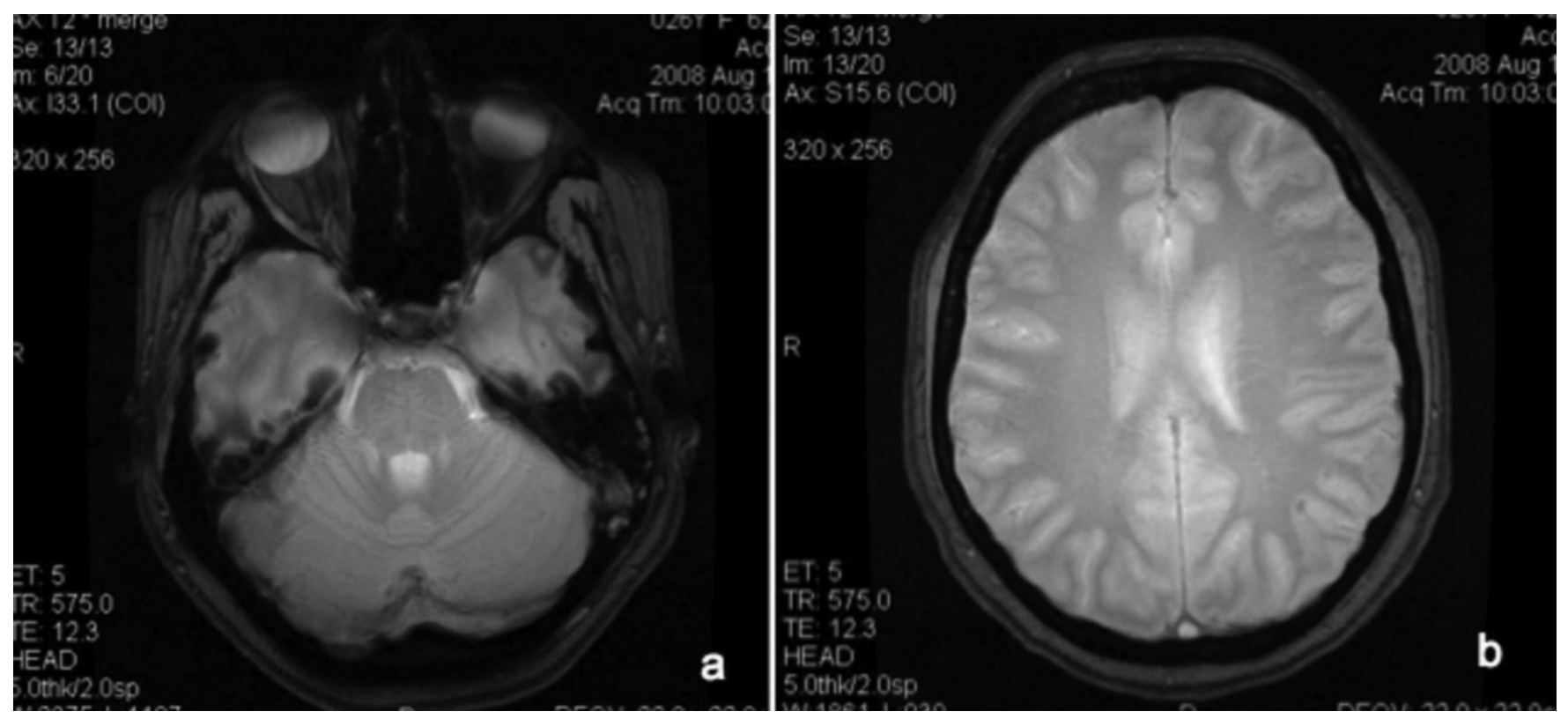

FIG. 4. Axial T2*-weighted gradient echo images showing increased intensity signal in the transverse sinus and SSS. 
rience with this technique differs from that reported in the literature (Fig. 4). Further studies with larger numbers of patients are required for clarifying this issue. Diffusion weighted images may not offer information regarding the establishment of diagnosis but provide information on the pathophysiology of CVST.14,15,49,72 Transcranial Doppler ultrasonography offers a noninvasive approach for diagnosis or follow-up of CVST, but the results are not sufficient for providing a valuable tool in the clinical setting.

\section{Laboratory Investigation}

Cerebral venous sinus thrombosis is a clinical entity that is strongly associated with genetic or acquired prothrombotic states. ${ }^{8,22,32,62}$ A thrombophilia check-up (antithrombin III, factor V Leiden, protein C and protein S levels, as well as prothrombin time, aPPT, and platelet count and functionality) should be routinely checked in patients suffering from CVST. An exhaustive laboratory workup for investigating the integrity of the thrombus formation and lysis mechanisms is of paramount importance in the evaluation of patients with CVST of no apparent cause.

Normal levels of D-dimers can aid in ruling out CVST in the vast majority of cases. ${ }^{11}$ However, normal D-dimer values cannot exclude the diagnosis of CVST; thus, in cases in which the sole presenting symptom is headache, the workup of these patients should include the appropriate imaging studies. ${ }^{8}$

Examination of CSF obtained via lumbar puncture should also be included in the evaluation of patients with possible CVST, particularly in those cases in which an infection is considered as the causative factor. . $^{8,32,62}$

The nonspecific and often misleading clinical presentation of CVST, along with the existence of no pathognomonic laboratory tests that can rule out CVST, makes the establishment of its diagnosis quite challenging. A possible diagnostic algorithm that can be followed in the evaluation of patients with suspected CVST is depicted in Fig. 5.

\section{Treatment}

The prompt treatment of patients with CVST should follow 4 directions to provide a complete treatment plan and maximize the chance of favorable outcome. Every effort should be made to identify and appropriately manage the predisposing and precipitating factors, administer antithrombotic therapy, lower and normalize the elevated ICP, and provide symptomatic treatment for seizures, headache, and visual disturbances. ${ }^{11,25,32,51}$ Interestingly, despite the large amount of research concerning CVST treatment, a limited number of studies exist in the literature fulfilling the criteria for developing treatment guidelines. ${ }^{18,25,26}$ The most recently published guidelines for the treatment of CVST have come from the EFNS 2006 task force, ${ }^{25}$ and mainly concern the administration of antithrombotic therapy, the management of the raised intracranial hypertension, and the efficient control of seizures.

The early identification of any predisposing factors or precipitating conditions is one of the most crucial steps in the treatment of CVST. The possibility of infection of the mastoids or paranasal sinuses should be investigated,

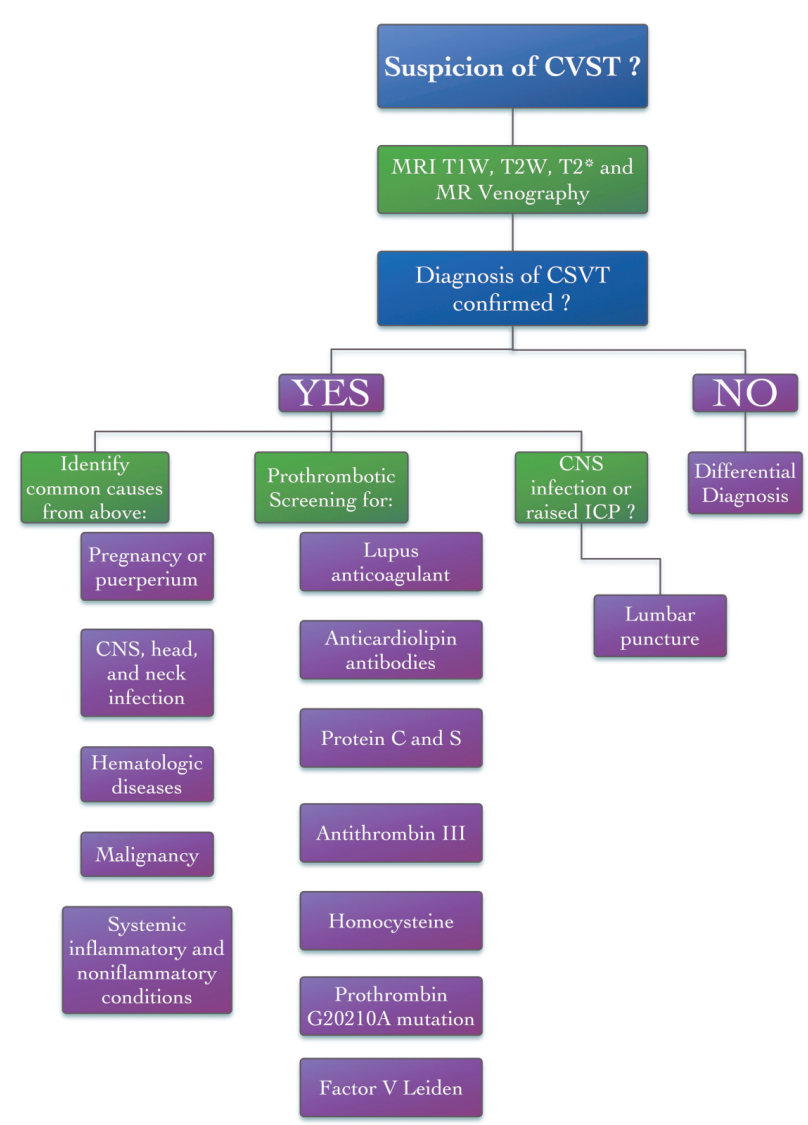

FIG. 5. Diagnostic algorithm for CVST. MRI = MR imaging; $T 2 W=T 2-$ weighted imaging; $\mathrm{T}^{*}=\mathrm{T} 2^{*}$-weighted gradient echo imaging.

and appropriate antibiotic therapy should be administered with no delay in such cases. Surgical debridement may be required in addition to antibiotic administration. Furthermore, in cases with acute deterioration, critical care support should always be considered. Surgical treatment of septic CVST should always include the administration of a combination of a third-generation cephalosporin and metronidazole. ${ }^{29}$

The role of antithrombotic treatment in the management of CVST has been well outlined. A meta-analysis study by Stam et al., ${ }^{63}$ which included 2 randomized controlled studies investigating the role of nonfractioned heparin ${ }^{26}$ and $\mathrm{LMWH},{ }^{18}$ revealed that anticoagulant treatment is safe and is associated with a reduction of the CVST-associated morbidity and mortality. However, their results did not reach the level of statistical significance. ${ }^{63}$ It has to be emphasized that the presence of intracerebral hemorrhage in cases of CVST is not a contraindication for appropriate anticoagulation therapy. ${ }^{25}$ There is no general consensus regarding the administration of intravenous heparin or subcutaneous LMWH. There is only indirect evidence in studies concerning extracerebral thromboembolism, which have demonstrated that LMWH is a more efficient treatment with a safer profile and fewer complications. ${ }^{66}$ Further research has to be undertaken to confirm this observation in patients with CVST. According to the most recent EFNS guidelines, ${ }^{25}$ patients with CVST without any contraindications for antithrombotic treatment 


\section{Cerebral venous sinus thrombosis}
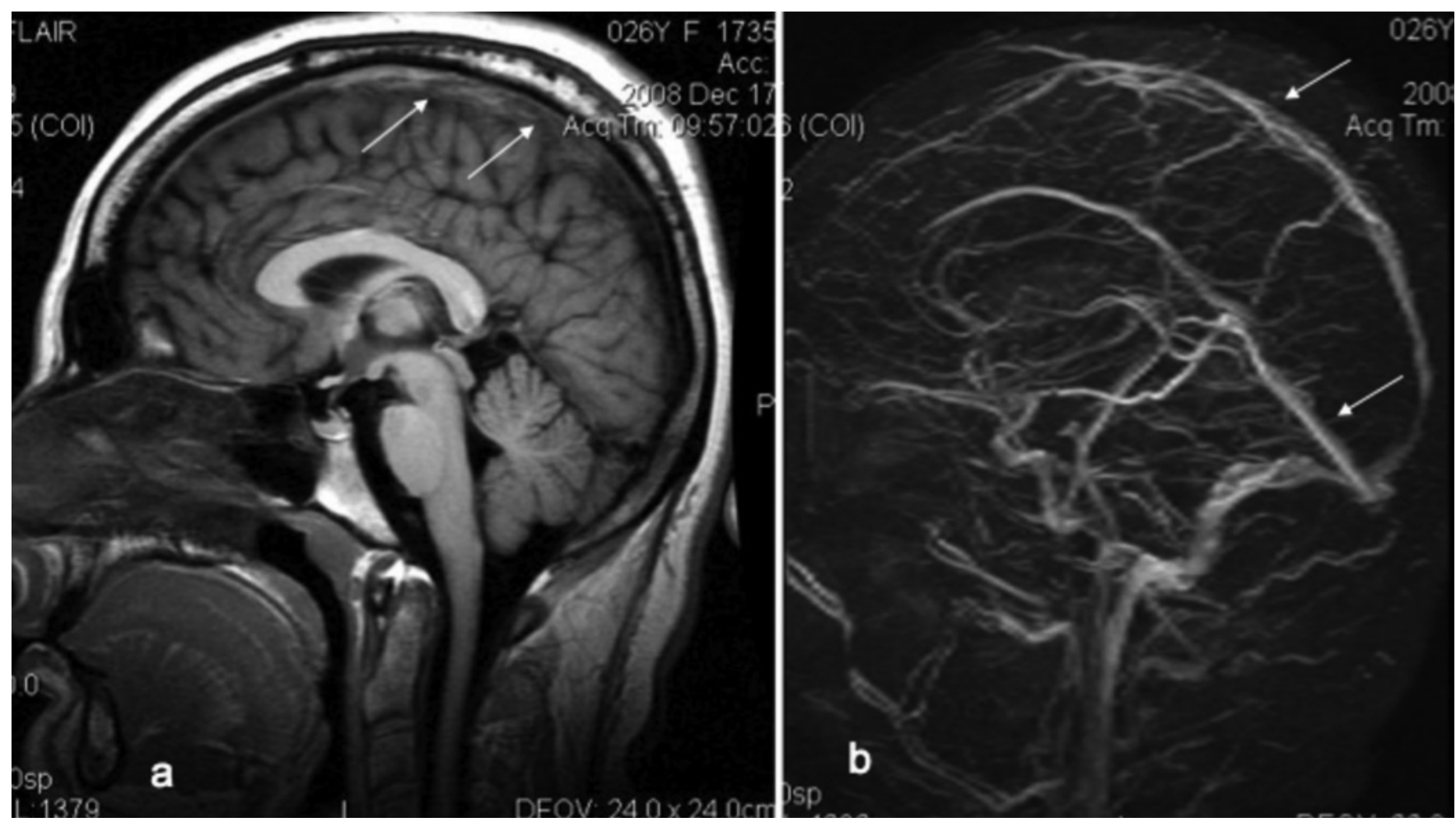

FIG. 6. Sagittal T1-weighted MR image and 2D MR venography obtained at the 3-month follow-up showing recanalization of the SSS (arrows).

should be treated either with subcutaneous body-weightadjusted LMWH (180 antifactor Xa U/kg/24 hours administered using 2 subcutaneous injections daily) or with dose-adjusted intravenous heparin targeting twice the normal aPTT values. It needs to be emphasized that if intravenous heparin should be stopped in the case of bleeding complications or necessary surgical intervention, the aPTT values usually normalize within 1-2 hours. ${ }^{9,25,28,51}$

Oral antithrombotic therapy should be administered in patients with CVST after the acute antithrombotic treatment. Nevertheless, the appropriate duration of antithrombotic therapy has not been established by any randomized controlled studies. The therapy target should be an international normalized ratio range between 2 and 3 , by using vitamin $K$ antagonists for 3 months when the underlying cause of CVST was transient and was properly corrected. In those cases in which CVST is idiopathic or related to "mild" thrombophilia, then the oral antithrombotic therapy should last for 6-12 months. In patients with CVST due to severe thrombophilia (the presence of 2 or more prothrombotic factors or antiphospholipid syndrome), then the oral anticoagulation treatment should be administered for life.

It is well known that elevated ICP can lead to secondary brain injury. Thus, special measures should be undertaken in the form of therapeutic lumbar punctures, acetazolamide administration, external ventricular drainage, or CSF shunt insertion. ${ }^{53}$ Decompressive craniectomy should be considered in patients with CVST whose condition deteriorates due to large intracerebral hemorrhages. ${ }^{25,28,51}$ There are not sufficient data justifying the employment of craniectomy in these patients, and further research is necessary for outlining the role of this procedure. ${ }^{25,28,51}$ In the acute phase of the CVST, cerebral edema may be present and should be appropriately treated with mannitol or hypertonic saline solutions. ${ }^{28}$

There is an increased frequency of seizures, especially in patients with supratentorial hemorrhagic lesions secondary to CVST. ${ }^{31}$ Anticonvulsant therapy should be administered in patients with CVST showing neurological deficits or harboring focal cerebral lesions. Ferro et al. ${ }^{31}$ recommended the administration of anticonvulsant treatment not only in CVST patients with seizures but also prophylactically in those patients who show supratentorial hemorrhagic lesions or present with motor deficits.

The option of endovascular treatment in CVST is not included in the existing treatment guidelines. This treatment modality carries some theoretical advantages compared with conservative management, but there are currently no randomized controlled study data available examining the actual efficacy and safety of this procedure. The method is usually performed under general anesthesia and requires highly trained physicians and well-organized centers and facilities. The employment of urokinase ${ }^{61}$ or recombinant tissue plasminogen activator $^{73}$ administration has been reported in a number of cases with unsuccessful anticoagulation. Yet, there are not sufficient data regarding the proper dosage, the route of administration, and the safety of this procedure. ${ }^{9}$ Canhão et al. ${ }^{9}$ summarized the data of the administration of urokinase or recombinant tissue plasminogen activator in CVST and found that these patients had higher rates of intracranial hemorrhage, especially in those with preexisting intracerebral hemorrhage. Thus, endovascular throm- 
TABLE 1: Cerebral venous sinus thrombosis causes and risk factors*

\begin{tabular}{|c|c|}
\hline Genetic Prothrombotic States & Hematology \\
\hline $\begin{array}{l}\text { antithrombin deficiency } \\
\text { protein } \mathrm{C} \text { and } \mathrm{S} \text { deficiency } \\
\text { resistance to activated protein C } \\
\text { factor V Leiden mutation } \\
\text { prothrombin mutation (A-G at position 20210) } \\
\text { methylenetetrahydrofolate reductase (MTHFR) } \\
\text { mutations leading to homocysteinemia }\end{array}$ & $\begin{array}{l}\text { polycythemia } \\
\text { thrombotic thrombocytopenic purpura } \\
\text { thrombocythemia } \\
\text { severe anemia and autoimmune hemolytic } \\
\text { anemia } \\
\text { paroxysmal nocturnal hemoglobinuria } \\
\text { heparin-induced thrombocytopenia }\end{array}$ \\
\hline Acquired Prothrombotic States & Drugs \\
\hline $\begin{array}{l}\text { pregnancy } \\
\text { puerperium } \\
\text { homocysteinemia } \\
\text { antiphospholipid antibody } \\
\text { nephrotic syndrome }\end{array}$ & $\begin{array}{l}\text { oral contraceptives } \\
\text { lithium, androgens } \\
\text { sumatriptan } \\
\text { intravenous immunoglobulin } \\
\text { hormone replacement therapy } \\
\text { asparaginase } \\
\text { steroids } \\
\text { illicit drugs (such as ecstasy) }\end{array}$ \\
\hline Infection & Mechanical Causes \\
\hline $\begin{array}{l}\text { meningitis } \\
\text { otitis } \\
\text { mastoiditis } \\
\text { sinusitis } \\
\text { neck, face, mouth infection } \\
\text { systemic infectious diseases } \\
\text { AIDS }\end{array}$ & $\begin{array}{l}\text { head trauma } \\
\text { neurosurgical procedures } \\
\text { jugular vein catheterization } \\
\text { lumbar puncture } \\
\text { injury to cerebral sinuses } \\
\text { intravenous drug abuse }\end{array}$ \\
\hline Inflammatory and Autoimmune Diseases & Other Causes \\
\hline $\begin{array}{l}\text { systemic lupus erythematosus } \\
\text { Adamantiades-Behçet disease } \\
\text { Wegener granulomatosis } \\
\text { sarcoidosis } \\
\text { inflammatory bowel disease } \\
\text { thromboangiitis obliterans }\end{array}$ & $\begin{array}{l}\text { dehydration, especially in children } \\
\text { thyrotoxicosis } \\
\text { arteriovenous malformations } \\
\text { dural fistulae } \\
\text { congenital heart disease } \\
\text { postradiation }\end{array}$ \\
\hline \multicolumn{2}{|l|}{ Malignancy } \\
\hline $\begin{array}{l}\text { CNS tumors } \\
\text { systemic malignancies } \\
\text { solid tumors outside CNS }\end{array}$ & \\
\hline
\end{tabular}

* The data for the construction of this table were obtained from reviews and original studies (references 2,8,11,29,32,62,68).

bolysis should not be used in patients with intracerebral hemorrhage and should be reserved for selected severe cases as a last treatment resort. ${ }^{51}$

\section{Our Institutional Management Protocol}

Early diagnosis of CVST is crucial and constitutes our first target in treating our patients with suspected CVST. The prolonged delay in establishing the CVST diagnosis among the patients included in the ISCVT may be explained by the nonspecific clinical presentation of these patients. ${ }^{32}$ Thus, CVST should be included in the differential diagnosis of patients presenting with suspicious clinical symptomatology especially if these patients are at high risk (because of pregnancy, puerperium, malignancy, use of oral contraceptives, paranasal or mastoid sinus, ear or meningeal infection, thrombophilias, and other factors).

In the cases in which the diagnosis of CVST is con- firmed by clinical data and neuroimaging studies, our next step is the identification of the underlying cause. Identification of an acquired prothrombotic condition as the underlying cause of CVST should be followed by removal or correction of this condition (such as discontinuing oral contraceptive pills). An extensive workup for thrombophilias is routinely performed in parallel with treatment efforts to reveal any genetic predisposing factors. In cases in which genetic thrombophilias are identified, a hematology consultation is necessary.

The next step in our current management protocol includes the clinical categorization of CVST according to the described 4 syndromes (isolated intracranial hypertension, focal neurological deficits, encephalopathy, and cavernous sinus syndrome) or their combinations. Every effort is made in the prophylaxis and symptomatic treatment of seizures, intracranial hypertension, headache, and/or visual disturbances. The cornerstone of CVST treatment is proper anticoagulation in the acute setting. 
The previously described EFNS guidelines are followed. This approach involves the use of intravenous heparin or subcutaneous LMWH. The effects of intravenous heparin intervention on aPTT can be reversed within 1-2 hours, $, 925,28,51$ whereas LMWH has a safer profile with fewer complications as indicated in studies for extracerebral thromboembolism. ${ }^{66}$ The possibility of sudden clinical deterioration and coma is always present; thus, close collaboration with the neurointensive unit is of paramount importance.

Oral anticoagulation therapy with vitamin $\mathrm{K}$ antagonists follows the acute treatment and is administered for 3 months or for as long as a lifetime duration, depending on the underlying cause. The target international normalized ratio for this therapy should range between 2 and 3. Transient causes of CVST are usually treated in our institution with 3-month oral anticoagulation therapy, patients with CVST due to mild thrombophilias usually take the proper dose of oral anticoagulation for 6-12 months, and patients with severe thrombophilias require lifetime treatment.

The treatment of patients with CVST usually requires a multidisciplinary approach, including specialists and close collaboration between the departments of hematology, neurology, neurosurgery, and neurointensive care.

\section{Outcome and Prognosis}

One of the greatest advances in the field of CVST is the change in outcome and prognosis of the disease throughout the years. In the past, CVST had been associated with a dismal prognosis and high mortality rate, reaching 30-50\%, ${ }^{5,54}$ Recent studies, ,32,37,64,65,68 and especially the ISCVT study, performed in the era of modern neuroimaging, LMWH administration, and endovascular intervention, reported much lower mortality rates (8$14 \%$ ) and significantly better outcome. A meta-analysis of 19 studies conducted by Dentali et al. ${ }^{22}$ showed that the mortality rate during the perihospitalization period was about $5.6 \%$, while at the end of the follow-up period, this percentage increased to $9.4 \% .^{21,22}$ In this study, complete or partial recovery was observed in $87.2 \%$ of patients, whereas $8.7 \%$ had a poor outcome with permanent neurological deficits. The recanalization rate was approximately $85 \%$ at 3 and 12 months, showing that this is a process that occurs early after the thrombotic event and remains stable thereafter (Fig. 6). The recurrence rate was estimated to be as high as $2.8 \%$. The authors concluded that CVST demonstrates a clinical entity with a low risk of death and good long-term prognosis in the modern era.

Poor outcome predictors are older age ( $>37$ years old), male sex, initial presentation with coma, seizures, focal neurological deficits, or altered mental status, associated cerebral deep venous thrombosis, intracranial hemorrhage, posterior fossa lesions, cancer, or infection..$^{10,32}$ The presence of any of the above factors with CVST predisposes one to increased morbidity and mortality. On the other hand, the presence of isolated intracranial hypertension was a predictor of favorable outcome. ${ }^{21,22}$ In those CVST cases in which fatal outcome occurs, the most common cause of death is transtentorial herniation due to the presence of a large intracerebral hemorrhage..$^{8,48}$

\section{Conclusions}

Cerebral venous sinus thrombosis constitutes a rare clinical entity. Genetic or acquired prothrombotic factors (such as deficiencies in anticoagulation-promoting proteins, usage of oral contraceptives, pregnancy, and/or malignancy) are the main causes in the western world, while infection remains the most common underlying cause in developing countries. The presenting clinical picture of CVST is nonspecific, may vary significantly, and makes the diagnosis of CVST quite puzzling. The employment of laboratory studies along with MR imaging and MR venography are necessary for establishing a diagnosis. Treatment follows the directions of identifying and eliminating the precipitating factor, anticoagulation administration, and aggressive intracranial hypertension management and anticonvulsive treatment when indicated. The role of endovascular thrombolysis and decompressive craniectomy in the management of severe CVST cases remains to be defined. The recent advances in early diagnosis and prompt management of CVST have significantly improved its prognosis.

\section{Disclaimer}

The authors report no conflict of interest concerning the materials or methods used in this study or the findings specified in this paper.

\section{References}

1. Agayev A, Yilmaz S: Images in clinical medicine. Cavernous sinus thrombosis. N Engl J Med 359:2266, 2008

2. Agnelli G, Verso M: Epidemiology of cerebral vein and sinus thrombosis. Front Neurol Neurosci 23:16-22, 2008

3. Alberti A, Venti M, Biagini S: Headache and cerebral vein and sinus thrombosis. Front Neurol Neurosci 23:89-95, 2008

4. Ameri A, Bousser MG: Cerebral venous thrombosis. Neurol Clin 10:87-111, 1992

5. Barnett HJ, Hyland HH: Noninfective intracranial venous thrombosis. Brain 76:36-49, 1953

6. Baumgartner RW, Studer A, Arnold M, Georgiadis D: Recanalisation of cerebral venous thrombosis. J Neurol Neurosurg Psychiatry 74:459-461, 2003

7. Biousse V, Ameri A, Bousser MG: Isolated intracranial hypertension as the only sign of cerebral venous thrombosis. Neurology 53:1537-1542, 1999

8. Bousser MG, Ferro JM: Cerebral venous thrombosis: an update. Lancet Neurol 6:162-170, 2007

9. Canhão P, Falcão F, Ferro JM: Thrombolytics for cerebral sinus thrombosis: a systematic review. Cerebrovasc Dis 15:159-166, 2003

10. Canhão P, Ferro JM, Lindgren AG, Bousser MG, Stam J, Barinagarrementeria F, et al: Causes and predictors of death in cerebral venous thrombosis. Stroke 36:1720-1725, 2005

11. Canhão P, Ferro JM, Stam J: Cerebral venous thrombosis, in Vinken PJ, Bruyn GW (eds): Handbook of Clinical Neurology. Amsterdam: Elsevier, 2008, pp 809-822

12. Cantú C, Barinagarrementeria F: Cerebral venous thrombosis associated with pregnancy and puerperium. Review of 67 cases. Stroke 24:1880-1884, 1993

13. Chen WL, Chang SH, Chen JH, Wu YL: Isolated headache as the sole manifestation of dural sinus thrombosis: a case report with literature review. Am J Emerg Med 25:218-219, 2007

14. Chu K, Kang DW, Yoon BW, Roh JK: Diffusion-weighted 


\section{A. Filippidis et al.}

magnetic resonance in cerebral venous thrombosis. Arch Neurol 58:1569-1576, 2001

15. Corvol JC, Oppenheim C, Manaï R, Logak M, Dormont D, Samson Y, et al: Diffusion-weighted magnetic resonance imaging in a case of cerebral venous thrombosis. Stroke 29: 2649-2652, 1998

16. Cumurciuc R, Crassard I, Sarov M, Valade D, Bousser MG: Headache as the only neurological sign of cerebral venous thrombosis: a series of 17 cases. J Neurol Neurosurg Psychiatry 76:1084-1087, 2005

17. de Bruijn SF, de Haan RJ, Stam J: Clinical features and prognostic factors of cerebral venous sinus thrombosis in a prospective series of 59 patients. For The Cerebral Venous Sinus Thrombosis Study Group. J Neurol Neurosurg Psychiatry 70:105-108, 2001

18. de Bruijn SF, Stam J: Randomized, placebo-controlled trial of anticoagulant treatment with low-molecular-weight heparin for cerebral sinus thrombosis. Stroke 30:484-488, 1999

19. de Bruijn SF, Stam J, Kappelle LJ: Thunderclap headache as first symptom of cerebral venous sinus thrombosis. CVST Study Group. Lancet 348:1623-1625, 1996

20. de Bruijn SF, Stam J, Vandenbroucke JP: Increased risk of cerebral venous sinus thrombosis with third-generation oral contraceptives. Cerebral Venous Sinus Thrombosis Study Group. Lancet 351:1404, 1998

21. Dentali F: Natural history of cerebral vein thrombosis: a systematic review. Blood 108:1129-1134, 2006

22. Dentali F, Crowther M, Ageno W: Thrombophilic abnormalities, oral contraceptives, and risk of cerebral vein thrombosis: a meta-analysis. Blood 107:2766-2773, 2006

23. Deveber G, Andrew M, Adams C, Bjornson B, Booth F, Buckley DJ, et al: Cerebral sinovenous thrombosis in children. $\mathbf{N}$ Engl J Med 345:417-423, 2001

24. Ebright JR, Pace MT, Niazi AF: Septic thrombosis of the cavernous sinuses. Arch Intern Med 161:2671-2676, 2001

25. Einhäupl K, Bousser MG, de Bruijn SF, Ferro JM, Martinelli I, Masuhr F, et al: EFNS guideline on the treatment of cerebral venous and sinus thrombosis. Eur J Neurol 13:553-559, 2006

26. Einhäupl KM, Villringer A, Meister W, Mehraein S, Garner C, Pellkofer M, et al: Heparin treatment in sinus venous thrombosis. Lancet 338:597-600, 1991

27. Ferro JM: Causes, predictors of death, and antithrombotic treatment in cerebral venous thrombosis. Clin Adv Hematol Oncol 4: 732-733, 2006

28. Ferro JM, Canhão P: Acute treatment of cerebral venous and dural sinus thrombosis. Curr Treat Options Neurol 10:126137,2008

29. Ferro JM, Canhão P: Cerebral venous and dural sinus thrombosis. Pract Neurol 3:214-219, 2003

30. Ferro JM, Canhão P, Bousser MG, Stam J, Barinagarrementeria F, ISCVT Investigators: Cerebral vein and dural sinus thrombosis in elderly patients. Stroke 36:1927-1932, 2005

31. Ferro JM, Canhão P, Bousser MG, Stam J, Barinagarrementeria F, ISCVT Investigators: Early seizures in cerebral vein and dural sinus thrombosis: risk factors and role of antiepileptics. Stroke 39:1152-1158, 2008

32. Ferro JM, Canhão P, Stam J, Bousser MG, Barinagarrementeria F, ISCVT Investigators: Prognosis of cerebral vein and dural sinus thrombosis: results of the International Study on Cerebral Vein and Dural Sinus Thrombosis (ISCVT). Stroke 35:664-670, 2004

33. Ferro JM, Correia M, Pontes C, Baptista MV, Pita F; CVTPCSG (Venoport): Cerebral vein and dural sinus thrombosis in Portugal: 1980-1998. Cerebrovasc Dis 11:177-182, 2001

34. Ferro JM, Lopes MG, Rosas MJ, Fontes J, Investigators V: Delay in hospital admission of patients with cerebral vein and dural sinus thrombosis. Cerebrovasc Dis 19:152-156, 2005

35. Ferro JM, Morgado C, Sousa R, Canhão P: Interobserver agreement in the magnetic resonance location of cerebral vein and dural sinus thrombosis. Eur J Neurol 14:353-356, 2007

36. Gadelha T, André C, Jucá AA, Nucci M: Prothrombin 20210A and oral contraceptive use as risk factors for cerebral venous thrombosis. Cerebrovasc Dis 19:49-52, 2005

37. Girot M, Ferro JM, Canhão P, Stam J, Bousser MG, Barinagarrementeria F, et al: Predictors of outcome in patients with cerebral venous thrombosis and intracerebral hemorrhage. Stroke 38:337-342, 2007

38. Gotoh M, Ohmoto T, Kuyama H: Experimental study of venous circulatory disturbance by dural sinus occlusion. Acta Neurochir (Wien) 124:120-126, 1993

39. Gowers WR: Manual of Diseases of the Nervous System, ed 2. London: Churchill, 1888

40. Heller C, Heinecke A, Junker R, Knöfler R, Kosch A, Kurnik $\mathrm{K}$, et al: Cerebral venous thrombosis in children: a multifactorial origin. Circulation 108:1362-1367, 2003

41. Jick SS, Jick H: Cerebral venous sinus thrombosis in users of four hormonal contraceptives: levonorgestrel-containing oral contraceptives, norgestimate-containing oral contraceptives, desogestrel-containing oral contraceptives and the contraceptive patch. Contraception 74:290-292, 2006

42. Kalbag R, Woolf A: Cerebral Venous Thrombosis. London: Oxford University Press, 1967

43. Khealani BA, Wasay M, Saadah M, Sultana E, Mustafa S, Khan FS, et al: Cerebral venous thrombosis: a descriptive multicenter study of patients in Pakistan and Middle East. Stroke 39:2707-2711, 2008

44. Krayenbühl HA: Cerebral venous and sinus thrombosis. Clin Neurosurg 14:1-24, 1966

45. Lanska DJ, Kryscio RJ: Risk factors for peripartum and postpartum stroke and intracranial venous thrombosis. Stroke 31:1274-1282, 2000

46. Lanska DJ, Kryscio RJ: Stroke and intracranial venous thrombosis during pregnancy and puerperium. Neurology 51:16221628,1998

47. Leach JL, Fortuna RB, Jones BV, Gaskill-Shipley MF: Imaging of cerebral venous thrombosis: current techniques, spectrum of findings, and diagnostic pitfalls. Radiographics 26 (1 Suppl):S19-S41, 2006

48. Lindgren A: Long-term prognosis of cerebral vein and sinus thrombosis. Front Neurol Neurosci 23:172-178, 2008

49. Lövblad KO, Bassetti C, Schneider J, Ozdoba C, Remonda L, Schroth G: Diffusion-weighted MRI suggests the coexistence of cytotoxic and vasogenic oedema in a case of deep cerebral venous thrombosis. Neuroradiology 42:728-731, 2000

50. Martinelli I, Taioli E, Palli D, Mannucci PM: Risk of cerebral vein thrombosis and oral contraceptives. Lancet 352:326, 1998

51. Masuhr F, Einhäupl K: Treatment of cerebral venous and sinus thrombosis. Front Neurol Neurosci 23:132-143, 2008

52. Masuhr F, Mehraein S, Einhäupl K: Cerebral venous and sinus thrombosis. J Neurol 251:11-23, 2004

53. Mullen MT, Sansing LH, Hurst RW, Weigele JB, Polasani RS, Messé SR: Obstructive hydrocephalus from venous sinus thrombosis. Neurocrit Care 10:359-362, 2008

54. Nagpal RD: Dural sinus and cerebral venous thrombosis. Neurosurg Rev 6:155-160, 1983

55. Paciaroni M, Palmerini F, Bogousslavsky J: Clinical presentations of cerebral vein and sinus thrombosis. Front Neurol Neurosci 23:77-88, 2008

56. Poon CS, Chang JK, Swarnkar A, Johnson MH, Wasenko J: Radiologic diagnosis of cerebral venous thrombosis: pictorial review. AJR Am J Roentgenol 189:S64-S75, 2007

57. Renowden S: Cerebral venous sinus thrombosis. Eur Radiol 14:215-226, 2004

58. Saadatnia M, Tajmirriahi M: Hormonal contraceptives as a risk factor for cerebral venous and sinus thrombosis. Acta 


\section{Cerebral venous sinus thrombosis}

Neurol Scand 115:295-300, 2007

59. Sébire G, Tabarki B, Saunders DE, Leroy I, Liesner R, SaintMartin C, et al: Cerebral venous sinus thrombosis in children: risk factors, presentation, diagnosis and outcome. Brain 128:477-489, 2005

60. Stam J: Cerebral venous and sinus thrombosis: incidence and causes. Adv Neurol 92:225-232, 2003

61. Stam J: Sinus thrombosis should be treated with anticoagulation. Arch Neurol 65:984-985, 2008

62. Stam J: Thrombosis of the cerebral veins and sinuses. N Engl J Med 352:1791-1798, 2005

63. Stam J, de Bruijn SF, Deveber G: Anticoagulation for cerebral sinus thrombosis. Cochrane Database Syst Rev:CD002005, 2002

64. Stolz E, Rahimi A, Gerriets T, Kraus J, Kaps M: Cerebral venous thrombosis: an all or nothing disease? Prognostic factors and long-term outcome. Clin Neurol Neurosurg 107:99-107, 2005

65. Stolz E, Trittmacher S, Rahimi A, Gerriets T, Röttger C, Siekmann R, et al: Influence of recanalization on outcome in dural sinus thrombosis: a prospective study. Stroke 35:544-547, 2004

66. van Dongen CJ, van den Belt AG, Prins MH, Lensing AW: Fixed dose subcutaneous low molecular weight heparins versus adjusted dose unfractionated heparin for venous thromboembolism. Cochrane Database Syst Rev:CD001100, 2004

67. Villringer A, Mehraein S, Einhäupl KM: Pathophysiological aspects of cerebral sinus venous thrombosis (SVT). J Neuroradiol 21:72-80, 1994

68. Wasay M, Bakshi R, Bobustuc G, Kojan S, Sheikh Z, Dai A, et al: Cerebral venous thrombosis: analysis of a multicenter cohort from the United States. J Stroke Cerebrovasc Dis 17:49-54, 2008

69. Wasay M, Dai AI, Ansari M, Shaikh Z, Roach ES: Cerebral venous sinus thrombosis in children: a multicenter cohort from the United States. J Child Neurol 23:26-31, 2008

70. White JB, Kaufmann TJ, Kallmes DF: Venous sinus thrombosis: a misdiagnosis using MR angiography. Neurocrit Care 8:290-292, 2008

71. Wu YW, Miller SP, Chin K, Collins AE, Lomeli SC, Chuang NA, et al: Multiple risk factors in neonatal sinovenous thrombosis. Neurology 59:438-440, 2002

72. Yoshikawa T, Abe O, Tsuchiya K, Okubo T, Tobe K, Masumoto $\mathrm{T}$, et al: Diffusion-weighted magnetic resonance imaging of dural sinus thrombosis. Neuroradiology 44:481-488, 2002

73. Zhang A, Collinson RL, Hurst RW, Weigele JB: Rheolytic thrombectomy for cerebral sinus thrombosis. Neurocrit Care 9:17-26, 2008

74. Zouaoui A, Hidden G: Cerebral venous sinuses: anatomical variants or thrombosis? Acta Anat (Basel) 133:318-324, 1988

Manuscript submitted July 15, 2009.

Accepted August 27, 2009.

Address correspondence to: Kostas N. Fountas, M.D., Ph.D., Department of Neurosurgery, Building A, Fl 3, Suite 57, University Hospital of Larissa, Mezourlo Larissa, Greece. email: fountas@ med.uth.gr. 